\title{
The function of body coloration of the hai coral snake Sinomicrurus japonicus boettgeri
}

\author{
Koji Mochida ${ }^{*}$, Wan-Yu Zhang ${ }^{2}$ and Mamoru Toda ${ }^{1}$
}

\begin{abstract}
Background: Prey animals often protect themselves from visual hunting predators via their body coloration, which encompasses various visual effects. When a prey animal displays a certain color pattern on its body surface, its protective function and effect are largely dependent on how a predator would encounter and perceive the prey animal. Asian coral snakes of the genus Sinomicrurus, which are venomous, display black bands and stripes on their orange body coloration. The banded pattern has been characterized as an aposematic signal in the New World coral snakes, but the stripes generally occur in cryptic snakes. We investigated the function of this complex color pattern, which might be interpreted as aposematic and cryptic, in Sinomicrurus japonicus boettgeri.

Results: First, plasticine replica experiments were conducted to assess whether natural avian predators avoid the color pattern of S. japonicus boettgeri; the results showed that they attacked the coral snake replicas and the control replicas with coloration similar to another prey snake, suggesting that the body coloration of S. japonicus boettgeri did not function aposematically in the wild. Second, we evaluated the chromatic contrast of the snake coloration with backgrounds from their natural habitats based on the avian predator visual systems. The body coloration of S. japonicus boettgeri showed the same, or lower, contrast levels with natural backgrounds than those of sympatric cryptic snakes, suggesting that the coloration was ineffective as an aposematic signal.
\end{abstract}

Conclusions: These results imply that the body coloration of S. japonicus boettgeri would work as crypsis through background matching or disruptive camouflage rather than aposematism.

Keywords: Aposematism; Disruptive coloration; Background matching; Coral snake mimicry

\section{Background}

Animals can protect themselves from visual hunting predators using their body coloration. They display a wide range of coloration and patterns, bearing several visual effects to reduce the risk of being detected by predators (e.g., background matching, disruptive camouflage, and optical illusion), to advertise their unprofitability for predators (aposematism) or to deceive predators into misidentifying it as something else (e.g., mimicry and masquerade) (Cott 1940; Edmunds 1974; Ruxton et al. 2004). More than one visual effect might coexist on the body surface of a prey animal, as the function of protective coloration often changes depending on the circumstances of when and where prey animals encounter predators (Hailman 1977; Tullberg et al. 2005; Bohlin

\footnotetext{
* Correspondence: kj.mochida@gmail.com

${ }^{1}$ Tropical Biosphere Research Center, University of Ryukyus, Nishihara, Okinawa 903-0213, Japan

Full list of author information is available at the end of the article
}

et al. 2008). When prey animals use different visual effects, such as crypsis and aposematism, these often exploit similar features of their predator's visual perception (Stevens 2007). The physiological abilities of the predators to detect and identify objects might also enhance or suppress the potency of the defense (Exnerovà et al. 2003; Mochida 2011; Valkonen et al. 2012), and considering the perception of the predator in quantitative color analysis of any protective coloration is therefore critical (Endler and Mielke 2005). Thus, various theoretical frameworks and techniques have been developed in the study of visual signals (Endler and Mielke 2005; Stevens 2007).

Snakes are one of the most useful groups for understanding the processes involved in visual signal design in predator-prey relationships, as they would often display the protective coloration on their body surface, and the coloration is classified broadly into three types generated 
by a relatively simple number of pattern elements: longitudinal stripes, spots (blotches or unicolored-speckled), and transverse bands (Murray and Myerscough 1991; Allen et al. 2013). Although most body coloration works cryptically through background matching, disruptive camouflage, or optical illusion (Brattstrom 1955; Jackson et al. 1976; Allen et al. 2013), some are used as aposematic signals (Green and McDiamond 1981; Pough 1988; Mappes et al. 2005). The New World coral snakes of the genera Micrurus and Micruroides, which are venomous, display red, yellow, white, and black transverse bands and are good examples of aposematism, as supported by laboratory and field experiments (Smith 1975; Brodie 1993; Brodie and Janzen 1995). Brodie (1993) conducted the field experiments using plasticine replicas of snakes to assess the function of the color pattern in coral snakes and showed that snake replicas with transverse bands, such as coral snakes, were rarely attacked by avian predators compared to plain control replicas, suggesting that the coral snake banded patterns functioned aposematically. Another study using plasticine snake replicas with a zigzag pattern, generally perceived as cryptic coloration, showed that the pattern had an aposematic function (Valkonen et al. 2011). Also, while the red or yellow coloration of the tropical snake is apparently conspicuous to the human eye, it would work as camouflage in their natural habitats from an avian predator's perspective (Wilson et al. 2007). Thus, if we are to understand how a particular coloration functions in nature, we need to consider how predators encounter and perceive their prey animals. This will provide new insights into the functional study of protective coloration, especially in cases in which prey animals display mismatched coloration in the wild and when that coloration is not effectively employed for defense (Stevens 2007).

The Asian coral snakes of the genus Sinomicrurus, the closest sister taxon of Micrurus and Micruroides, might have been expected to be aposematic, as they are venomous and display similar transverse bands to the New World coral snakes (Honma et al. 1967; Slowinski et al. 2001; Castoe et al. 2007). Notably, several species of Sinomicrurus exhibit not only transverse bands, but also longitudinal stripes on their body surfaces (Figure 1). The latter might be linked to cryptic defense, contrary to an aposematic strategy that makes the snake obvious against its background (Jackson et al. 1976). In this study, we investigated the function of the body coloration of Sinomicrurus japonicus boettgeri, which is distributed on several islands of the Ryukyu Archipelago, Japan, and whose body coloration consists of transverse bands and longitudinal stripes, which might be interpreted as both aposematism and crypsis. First, we conducted a plasticine replica experiment using plasticine snake replicas to assess whether natural avian predators avoided the color pattern of S. japonicus boettgeri as a prey item. Second, we measured the reflectance spectra of the body coloration of the snakes and constructed a tetrahedral color space to evaluate the chromatic contrasts with background objects, based on the visual systems of their avian predators (Endler and Mielke 2005; Stoddard and Prum 2008); these chromatic contrasts can produce several visual effects, such as background matching, disruptive camouflage, optical illusion, and aposematic signals on the body surface (Cott 1940; Gamberale-Stille 2001; Cuthill et al. 2005).

\section{Methods}

\section{Plasticine replica experiment}

We conducted plasticine replica experiments using natural avian predators in the mountain forests of Okinawajima Island, Ryukyu Archipelago, Japan. At the field site, $S$. japonicus boettgeri is active during the day and at night on the ground (Obara 2013; Mochida and Toda, personal observation). We constructed two types of snake
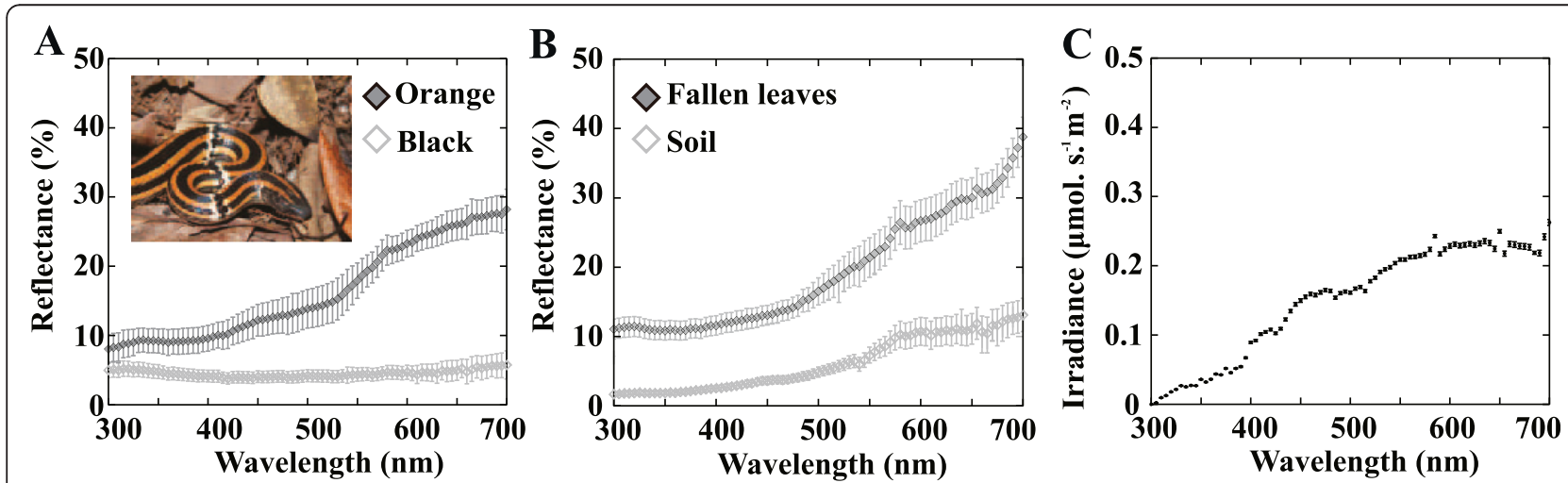

Figure 1 Body coloration of Sinomicrurus japonicus boettgeri and its color environments. Average reflectance spectra of two color elements of the body surface of S. japonicus boettgeri (A) and background subjects (B), and average irradiance of their habitats (C). Error bars indicate the standard error (SE). 
replicas using pre-colored plasticine (Sculpy-III; Polyform Products Co., Elk Grove Village, IL, USA) threaded onto an S-shaped wire frame (Brodie 1993). Coral snake replicas were painted black with narrow white transverse bands and black stripes on an orange surface similar to the body color pattern of S. japonicus boettgeri, and the control replicas were plain green, similar to Cyclophiops semicarinatus, which is another prey item of avian predators at the field site (Tanaka and Mori 2000). We verified that the coloration of the replicas did not exhibit appreciable difference in reflectance spectra to that of target snakes using a USB2000+ spectrometer (Ocean Optics, Dunedin, FL, USA) and that there were no snake species showing coloration and pattern similar to replicas except for target snakes. The size of both replicas was $10 \mathrm{~mm}$ diameter and $180 \mathrm{~mm}$ length. Both types of replica were placed into one location side by side, enabling the avian predators to choose a profitable prey item (Figure S1 in Additional file 1). If the body color pattern of S. japonicus boettgeri functions aposematically, avian predators would avoid predation attempts on replicas of a similar color pattern. The replica pairs were placed on forest floor 0.5 to $1.0 \mathrm{~m}$ from edge of mountain roads. We prepared two types of background, an artificial white board and natural backgrounds, as predators might not find them on natural backgrounds if both replicas were too cryptic for them to locate. In one experiment, 25 pairs of replicas were set on each background in an alternating arrangement. Fifty pairs of replicas were divided into three blocks at intervals of $2 \mathrm{~km}$, with each pair set at over 10-m intervals within a block. The number of pairs was from 12 to 20 in each block. After $72 \mathrm{~h}$, the replicas were collected, and the $\mathrm{U}$-shaped or V-shaped bill marks left by avian predators on the replicas were recorded as attacking attempts on them (Brodie 1993; Brodie and Janzen 1995; Valkonen et al. 2011). Multiple marks on one replica were scored as a single predation attempt. The experiments were conducted in November 2012 and June 2013, using a total of 100 pairs of snake replicas. November is the season when the snake-eating buzzard Butastur indicus is temporally abundant at the field site because of its migration from northern areas. Some of them remain there during winter, and then the numbers increase again in early spring until they disappear from the field site by May. Besides the buzzards, there are also a few avian species, which are potential predators on snakes, such as crows and kingfishers, throughout the year. Because some of the replicas were carried away from their original locations in the first experiment (see Results), both sides of the replicas were fixed to the ground in the second experiment.

\section{Color analysis}

The chromatic contrasts between the color elements of the snake body and background objects, and between the color elements within a snake body in S. japonicus boettgeri, were analyzed. These chromatic contrasts were compared to those of the two nonvenomous colubrid species, C. semicarinatus and Dinodon semicarinatum, and an ambush venomous pit viper, Ovophis okinavensis, all found on Okinawajima Island and living sympatrically with S. japonicus boettgeri. D. semicarinatum has large black blotches and a reddish white color, and the body coloration of O. okinavensis consists of small dark brown blotches on a light brown color surface (Figure S2 in Additional file 1). The main habitat of these four snake species is the forest floor, which is covered with red clay and fallen leaves. The reflectance spectra were measured of the orange and black color elements of $S$. japonicus boettgeri $(N=5)$, a green color element of $C$. semicarinatus $(N=5)$, the black and reddish-white color elements of D. semicarinatum $(N=8)$, and the light and dark brown color elements of $O$. okinavensis $(N=11)$. The spectra of the soil and fallen leaves in their habitats were analyzed as background color elements. For each background type, 20 subjects were measured. In these analyses, a USB2000+ spectrometer was used with a DTMini-2-GS deuterium and halogen light source (Ocean Optics, Dunedin, FL, USA). The average reflectance of each color element was calculated by computing the means from three replicate spectra measured for each subject for each data point between 300 and $700 \mathrm{~nm}$, expressed relative to a $99 \%$ white reflectance standard. Irradiance of their habitats was also measured using a USB2000+ spectrometer with a cosine adapter head. We used LS-1 CAL as the standard reflectance light. In April 2013, we measured the irradiance at three landscape locations in their habitats: the ridge, valley, and the gentle slope of the mountain forest, under full sun conditions between 10:00 and 14:00 h. The average irradiance of the habitat was calculated by computing the means from 10 irradiance data measures for each location for each data point between 300 and $700 \mathrm{~nm}$. To evaluate the chromatic contrasts of the snake body coloration, all color spectra data were mapped in a tetrahedral space, based on environmental irradiance and ultraviolet-sensitive (UVS) or violet-sensitive (VS) visual systems, as birds have two types of color vision (Endler and Mieke 2005). To calculate the chromatic contrast in the tetrahedral space, the coloration, represented by the color covering the largest surface area of each species, was set as the base color element (S. japonicus boettgeri; orange, C. semicarinatus; green, D. semicarinatum; black, and O. okinavensis; light brown). Based on these color elements, chromatic contrasts were calculated using formula (22) in Endler and Mieke (2005). We also calculated these contrasts based on a black color element that covers the second largest area of its body surface in S. japonicus boettgeri. C. semicarinatus shows plain green coloration; 
therefore, we did not calculate intrabody contrast in this species. Animals were handled and experiments were conducted in accord with the Guideline for Animal Experiments in University of the Ryukyus.

\section{Results}

In 25 of 100 replica pairs, replicas were either attacked by birds (16 replicas) or missing (26 replicas). In 17 of these 25 pairs, both replicas were attacked or missing. We found a difference in the number of avian predation attempts on the pairs of replicas between November (20/50 pairs) and June (5/50 pairs). No significant differences were observed in the number of replicas remaining after predation attempts between the coral snakes and controls on natural (McNemar pairwise test; $\chi^{2}=$ 36.54, $P>0.05)$ and white backgrounds $\left(\chi^{2}=40.02, P>\right.$ $0.05)$ when the 'missing' events were treated as nonpredation attempts. Small pieces of the replicas were often found at such 'missing' locations, suggesting that avian predation events were also assumed. The statistical results did not change when the 'missing' events were treated as predation attempts by birds (natural background; $\chi^{2}=25.52, P>0.05$, white background; $\chi^{2}=$ $10.02, P>0.05$ ) (Figure 2). Although we know that small mammals, which are distributed on the field sites, such as rats and mice, bite or shave the surface of plasticine replicas regardless of their shape (Mochida and Toda, unpublished data), there were few replicas showing such signs on their surface in this experiment.

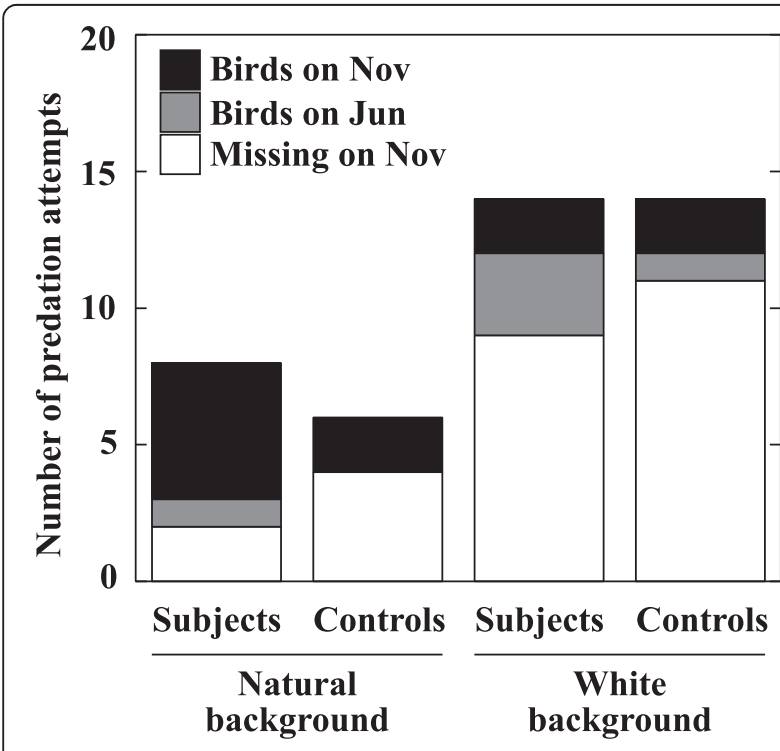

Figure $\mathbf{2}$ The number of avian attacks on snake replicas. Black and gray columns denote the number of attacking attempts on snake replicas in November and June, respectively. The white column indicates the number of missing replicas.
Color analyses based on environmental irradiance and two types of avian visual systems showed interspecific differences in intrabody contrasts (ANOVA: UVS system, $F_{2,21}=16.9272, P<0.0001$; VS system, $F_{2,21}=11.0245$, $P=0.0005$ ) and in background contrasts with soils (UVS system, $F_{3,25}=26.8817, P<0.0001 ;$ VS system, $F_{3,25}=$ 13.1676, $P<0.0001$ ) but not in fallen leaves (UVS system, $F_{3,25}=2.0281, P=0.1356$; VS system, $F_{3,25}=1.8053, P=$ 0.1720) (Figures 1 and 3; Table S1 in Additional file 1). The orange coloration of S. japonicus boettgeri had the same level or lower contrast with two types of backgrounds compared to that of the sympatric three species (Soil-UV type; $0.09 \pm 0.01$, Soil-V type; $0.08 \pm 0.01$, Fallen leaf-UV type; $0.06 \pm 0.01$. Fallen leaf- $V$ type; $0.06 \pm 0.02$ ), and its black coloration of transverse bands and stripes also showed similar reflectance curve, which produces same level background contrasts (Soil-UV type; $0.22 \pm$ 0.02 , Soil-V type; $0.18 \pm 0.02$, Fallen leaf-UV type; $0.14 \pm$ 0.02 . Fallen leaf- $\mathrm{V}$ type; $0.11 \pm 0.02$ ) to black elements of D. semicarinatum (Figure 1; Table S1 in Additional file 1).

\section{Discussion}

The plasticine replica experiments showed that the avian predators did not avoid attacking the coral snake replicas or the controls. Both replicas were identified as prey items by the predators, as C. semicarinatus has been known as a prey item of birds (Tanaka and Mori 2000). A previous study suggested that predators that specialized in feeding on snakes might disrupt plasticine replica experiments used for testing aposematic signals of prey, as these animals might be capable of coping with the secondary defenses of the snakes (Valkonen et al. 2012). In November, a snake-eating buzzard is temporally abundant. However, it appeared that another avian predator also attacked the coral snake replicas $(N=4)$ over the controls $(N=1)$ in June when the buzzards were not present, although the small sample size prevented any statistical significance in the differences of the number of replicas attacked by predators between the two types. Thus, our result suggested that the body color pattern of $S$. japonicus boettgeri did not function aposematically in the wild.

Our color analyses supported the above interpretation of the plasticine replica experiments. The body coloration of $S$. japonicus boettgeri had the same level or lower contrast with two types of backgrounds compared to that of the sympatric species, including the two cryptic species $C$. semicarinatus and $O$. okinavensis. The two background subjects had a similar curve of reflectance spectra to that of the orange coloration of S. japonicus boettgeri, leading to a decrease in contrast. Background matching and disruptive camouflage would work best when large sections of body coloration blended into the background (Cott 1940; Stevens et al. 2006; Stevens and Merilaita 2009), 


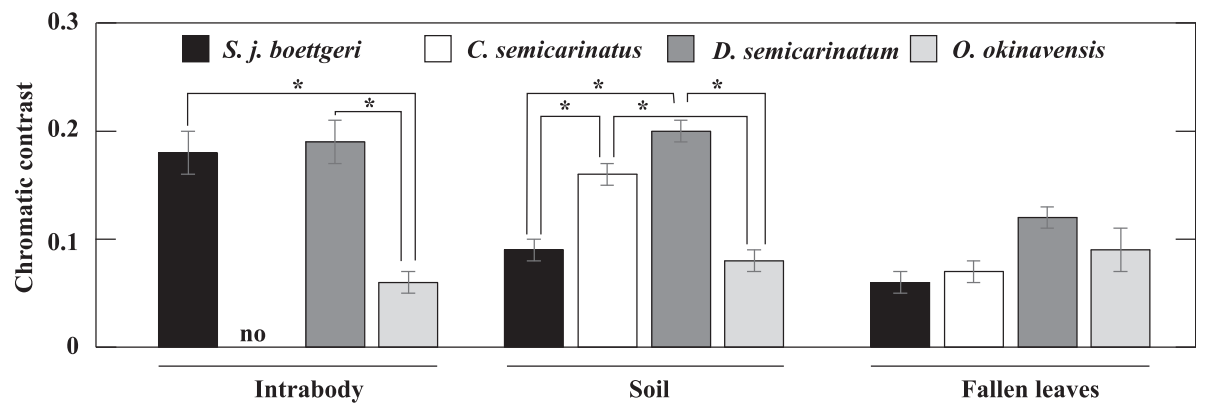

Figure 3 Chromatic contrasts of the body coloration of snakes based on the UV type of the avian visual system. Asterisks indicate significant differences in each chromatic contrast between species (Tukey-Kramer test: $P<0.05$ ). Error bars indicate the standard error (SE).

contrary to the aposematic signals that should show high contrasts with backgrounds (Gamberale-Stille 2001). In cryptic defense, low contrast with a background is not always a prerequisite, as a high contrast will still often induce the optical illusion when striped or banded snakes can move faster; this is known as the flicker-fusion effect (reviewed by Stevens 2007; Allen et al. 2013), but it might not applicable to $S$. japonicus boettgeri, which moves relatively slowly (Authors, personal observation). The roles played by intrabody contrast on disruptive camouflage and background matching through longitudinal stripes and transverse bands are controversial and not clear in snakes (Allen et al. 2013). Studies on butterflies showed that a high contrast within a body could enhance the disruptive effects to conceal the body outline compared to a low contrast with the background (Cuthill et al. 2005); however, too much contrast within a body might increase predation risks due to conspicuousness (Stobbe and Schaefer 2008). We did not test the effects of intrabody contrast of $S$. japonicus boettgeri on their defenses. A direct comparison of the chromatic contrasts of body coloration with New World coral snakes that have been confirmed as aposematic is needed, but our results suggested that the orange coloration of S. japonicus boettgeri with a black stripe and band patterns may work cryptically through background matching or disruptive camouflage rather than aposematism.

In the Ryukyu Archipelago, there are two subspecies, Sinomicrurus japonicus japonicus and Sinomicrurus japonicus takarai, and kin species, Sinomicrurus macclellandi iwasakii. S. japonicus japonicus and $S$. japonicus takarai display black longitudinal stripes on orange body coloration similar to S. japonicus boettgeri, and also S. japonicus takarai does not show transverse bands, implying that their body coloration may not function as an aposematic signal, as in the case of $S$. japonicus boettgeri. On the other hand, S. macclellandi iwasakii displays wide transverse bands throughout its entire body and has no longitudinal stripes, and therefore, its body color pattern is more similar to that of the
New World coral snakes than to other species of Sinomicrurus. S. macclellandi iwasakii is the most southerly distributed of the Sinomicrurus species in the Ryukyu Archipelago, and its distribution range overlaps with that of the resident raptor Spilornis cheela, a wellknown snake-eating predator. This coral snake might encounter avian predators at a higher frequency than other Sinomicrurus throughout the year in this region. Establishment of aposematism is advantageous for prey animals in cases when the predators can learn about the unprofitability of prey carrying aposematic signals (Mappes et al. 2005). Empirical studies have revealed that an abundance of visually oriented predators would drive the acquisition of aposematic defenses in prey animals (Ratcliffe and Nydam 2008; Mochida 2011). Further work is required to clarify the relationships between interspecific variation in body coloration and differences in local predator composition in Sinomicrurus, as well as considering the influences of their phylogenetic relationships and other defensive traits such as toxicity.

\section{Conclusion}

Our result implies that the body coloration of S. japonicus boettgeri would work as crypsis through background matching or disruptive camouflage rather than aposematism. This would give us an understanding as to when and where some Asian coral snakes lose and acquire their aposematic transverse bands and longitudinal stripes, which could be linked with crypsis.

\section{Additional file}

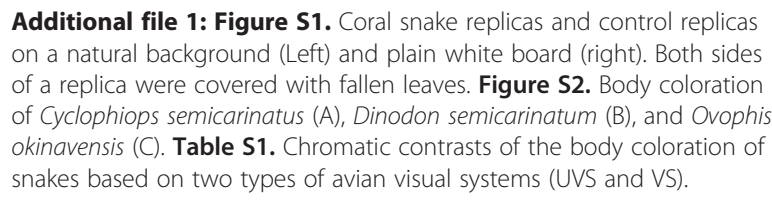

Additional file 1: Figure S1. Coral snake replicas and control replicas on a natural background (Left) and plain white board (right). Both sides of a replica were covered with fallen leaves. Figure S2. Body coloration of Cyclophiops semicarinatus (A), Dinodon semicarinatum (B), and Ovophis okinavensis (C). Table S1. Chromatic contrasts of the body coloration of snakes based on two types of avian visual systems (UVS and VS).

\section{Competing interests}

The authors declare that they have no competing interests. 


\section{Authors' contributions}

KM participated in the design of the study, conducted all experiments, analyzed data, and wrote the manuscript. WYZ also carried out the plasticine replica experiments. MT participated in the design of the study and wrote the manuscript. All authors read and approved the final manuscript.

\section{Acknowledgements}

We thank the Environmental Forest Yona Field, University of Ryukyus for support of this research. We are grateful for helps to collect the reflectance spectral data of snakes to T. Jono, Y. Kadota, T. Kaito, T. Otani, K. Terada, and A. Mori. T. Jono and T. Kaito also gave us good photographs. This study was financially supported by a JSPS Research Fellowship for Young Scientists and a Grant-in-Aid for Research Activity Start-up (228700159) to KM.

\section{Author details}

${ }^{1}$ Tropical Biosphere Research Center, University of Ryukyus, Nishihara, Okinawa 903-0213, Japan. ${ }^{2}$ Graduate School of Engineering and Science, University of Ryukyus, Nishihara, Okinawa 903-0213, Japan.

Received: 10 July 2014 Accepted: 2 February 2015

\section{Published online: 24 February 2015}

\section{References}

Allen WL, Baddeley R, Scott-Samuel NE, Cuthill IC (2013) The evolution and function of pattern diversity in snakes. Behav Ecol 24:1237-1250

Bohlin T, Tullberg BS, Merilaita S (2008) The effect of signal appearance and distance on detection risk in an aposematic butterfly larva (Parnassius apollo). Anim Behav 76:577-584

Brattstrom BH (1955) The coral snake 'mimic' problem and protective coloration. Evolution 9:217-219

Brodie ED III (1993) Differential avoidance of coral snake banded patterns by free-ranging avian predators in Costa Rica. Evolution 47:227-235

Brodie ED III, Janzen FJ (1995) Experimental studies of coral snake mimicry: generalized avoidance of ringed snake patterns by free-ranging avian predators. Funct Ecol 9:186-190

Castoe TA, Smith EN, Brown RM, Parkinson CL (2007) Higher-level phylogeny of Asian and American coralsnakes, their placement within the Elapidae (Squamata), and the systematic affinities of the enigmatic Asian coralsnake Hemibungarus calligaster (Wiegmann, 1834). Zool J Linn Soc 151:809-831

Cott HB (1940) Adaptive Coloration in Animals. Methuen, London

Cuthill IC, Stevens M, Sheppard J, Maddocks T, Párraga CA, Troscianko TS (2005) Disruptive coloration and background pattern matching. Nature 434:72-74

Edmunds M (1974) Defence in Animals: A Survey of Antipredator Defences. Longman, Essex

Endler JA, Mielke PW (2005) Comparing entire colour patterns as birds see them. Biol J Linn Soc 86:405-431

Exnerovà $\mathrm{A}$, Landovà $\mathrm{E}$, Stys $\mathrm{P}$, Fuchs $\mathrm{R}$, Prokopovà $\mathrm{M}$, Cehlàrikovà $\mathrm{P}$ (2003) Reactions of passerine birds to aposematic and nonaposematic firebugs (Pyrrhocoris apterus; Heteroptera). Biol J Linn Soc 78:517-525

Gamberale-Stille G (2001) Benefit by contrast: an experiment with live aposematic prey. Behav Ecol 12:768-772

Green HW, McDiamond RW (1981) Coral snake mimicry: does it occur? Science 213:1207-1212

Hailman JP (1977) Optical Signals. Indiana University Press, Bloomington

Honma M, Okonogi T, Kosuge T, Mishima S (1967) Studies on the toxicity of striped coral snake ("Hyan", Calliophis japanicus japanicus) venom. Nippon nettai igaku zasshi 8:65-69 (in Japanese)

Jackson JF, Ingram W III, Campbell HW (1976) The dorsal pigmentation pattern of snakes as an antipredator strategy: a multivariate approach. Am Nat 110:1029-1053

Mappes J, Marples N, Endler JA (2005) The complex business of survival by aposematism. Trens Ecol Evol 20:598-603

Mochida K (2011) Combination of local selection pressures drives diversity in aposematic signals. Evol Ecol 25:1017-1028

Murray JD, Myerscough MR (1991) Pigmentation pattern formation on snakes. J Theor Biol 149:339-360

Obara Y (2013) A case of predation on Achalinus werneri by Sinomicrurus japonicus boettgeri. AKAMATA 24:1-2 (in Japanese)

Pough FH (1988) Mimicry of vertebrates: are the rules different? Am Nat 131:S67-S102
Ratcliffe JM, Nydam ML (2008) Multimodal warning signals for a multiple predator world. Nature 455:96-99

Ruxton GD, Sherratt TN, Speed MP (2004) Avoiding Attack: The Evolutionary Ecology of Crypsis, Warning Signals \& Mimicry. Oxford University Press, New York

Slowinski JB, Boundy J, Lawson R (2001) The phylogenetic relationships of Asian coral snakes (Elapidae: Calliophis and Maticora) based on morphological and molecular characters. Herpetologica 57:233-245

Smith SM (1975) Innate recognition of coral snake pattern by a possible avian predator. Science 187:759-760

Stevens M (2007) Predator perception and the interrelation between different forms of protective coloration. Proc R Soc B 274:1457-1464

Stevens M, Merilaita S (2009) Defining disruptive coloration and distinguishing its functions. Philo Trans R Soc B 364:481-488

Stevens M, Cuthill IC, Windsor AMM, Walker HJ (2006) Disruptive contrast in animal camouflage. Proc R Soc B 273:2433-2438

Stobbe N, Schaefer HM (2008) Enhancement of chromatic contrast increases predation risk for striped butterflies. Proc R Soc B 275:1535-1541

Stoddard MC, Prum RO (2008) Evolution of avian plumage color in tetrahedral color space: a phylogenetic analysis of New World buntings. Am Nat 171:755-776

Tanaka K, Mori A (2000) Literature survey on predators of snakes in Japan. Current Herp 19:97-111

Tullberg BS, Merilaita S, Wiklund C (2005) Aposematism and crypsis combined as a result of distance dependence: Functional versatility of the colour pattern in the swallowtail butterfly larva. Proc R Soc B 272:1315-1321

Valkonen J, Niskanen M, Björklund M, Mappes J (2011) Disruption or aposematism? Significance of dorsal zigzag pattern of European vipers. Evol Ecol 25:1047-1063

Valkonen JK, Nokelainen O, Niskanen M, Kilpimaa J, Björklund M, Mappes J (2012) Variation in predator species abundance can cause variable selection pressures on warning signaling. Ecol Evol 2:1971-1976

Wilson D, Heinsohn R, Endler JA (2007) The adaptive significance of ontogenetic colour change in a tropical python. Biol Lett 3:40-43

\section{Submit your manuscript to a SpringerOpen ${ }^{\odot}$ journal and benefit from:}

- Convenient online submission

Rigorous peer review

- Immediate publication on acceptance

- Open access: articles freely available online

- High visibility within the field

- Retaining the copyright to your article

Submit your next manuscript at $>$ springeropen.com 